\title{
Effect of veratric acid and 3,4-dimethylphenyl-anthranilic acid on the corrosion and electrochemical behavior of cadmium, bismuth, and their alloy in a borate solution
}

\section{A. G. Berezhnaya,* V. I. Mishurov, V. V. Ekilik and Sh. Z. Lomidze}

Southern Federal University, ul. Zorge 7, Rostov-on-Don, 344090 Russian Federation

*E-mail:ber@sfedu.ru

\begin{abstract}
The corrosion and electrochemical behavior of cadmium, bismuth, and a cadmium-bismuth alloy containing $50 \mathrm{wt} . \%$ of cadmium, in pure borate neutral solution and with addition of veratric and 3,4-dimethylphenylanthranilic acids is compared. It is shown that veratric acid has a more significant effect on the corrosion and anodic dissolution of the metals, whereas 3,4-dimethylphenylanthranilic acid more strongly affects the alloy behavior.
\end{abstract}

Key words: cadmium, bismuth, eutectic alloys, veratric acid, 3,4-dimetylphenylanthranilic acid, anodic dissolution.

Received: August 27, 2013.

doi: $\underline{10.17675 / 2305-6894-2013-2-4-311-317}$

\section{Introduction}

Previously, benzotriazole [1,2], organic quaternary ammonium perchlorates, and their mixtures with sodium sulfate or halides were studied as inhibitors of the anodic dissolution of cadmium, bismuth, and their alloys in a borate neutral solution [3]. The aim of this work was to compare the corrosion and electrochemical behavior of cadmium, bismuth and $\mathrm{Cd} 50 \mathrm{Bi}$ alloy in a neutral borate solution in the presence of veratric and 3,4dimethylphenylanthranilic acids.

\section{Experimental}

The cadmium - bismuth alloy containing $50 \mathrm{wt} . \%$ of cadmium was prepared by melting the components in evacuated glass tubes. Electrodes with a disk-shaped working surface of about $0.28 \mathrm{~cm}^{2}$ reinforced with cured epoxy resin were mechanically abraded and polished.

Polarization curves were recorded in a temperature-controlled $\left(25 \pm 0.2^{\circ} \mathrm{C}\right)$ threeelectrode cell with stepwise potential $(E)$ variation using $50 \mathrm{mV}$ steps and 1 min exposure at each $E$. The $E$ values are reported with respect to a saturated silver chloride electrode. All studies were carried out in borate solution ( $\mathrm{pH}$ 7.4) deaerated with purified hydrogen, without or with addition of veratric acid (VA) or 3,4-dimethylphenylanthranilic acid (DMPhAA) at concentration $C=0.1 \mathrm{mM}$. The effect of additives was estimated by inhibition factor $\gamma$, which is the ratio of the process rates without and with an additive. 


\section{Results and Discussion}

In neutral borate solution, cadmium undergoes anodic passivation, Fig. 1.

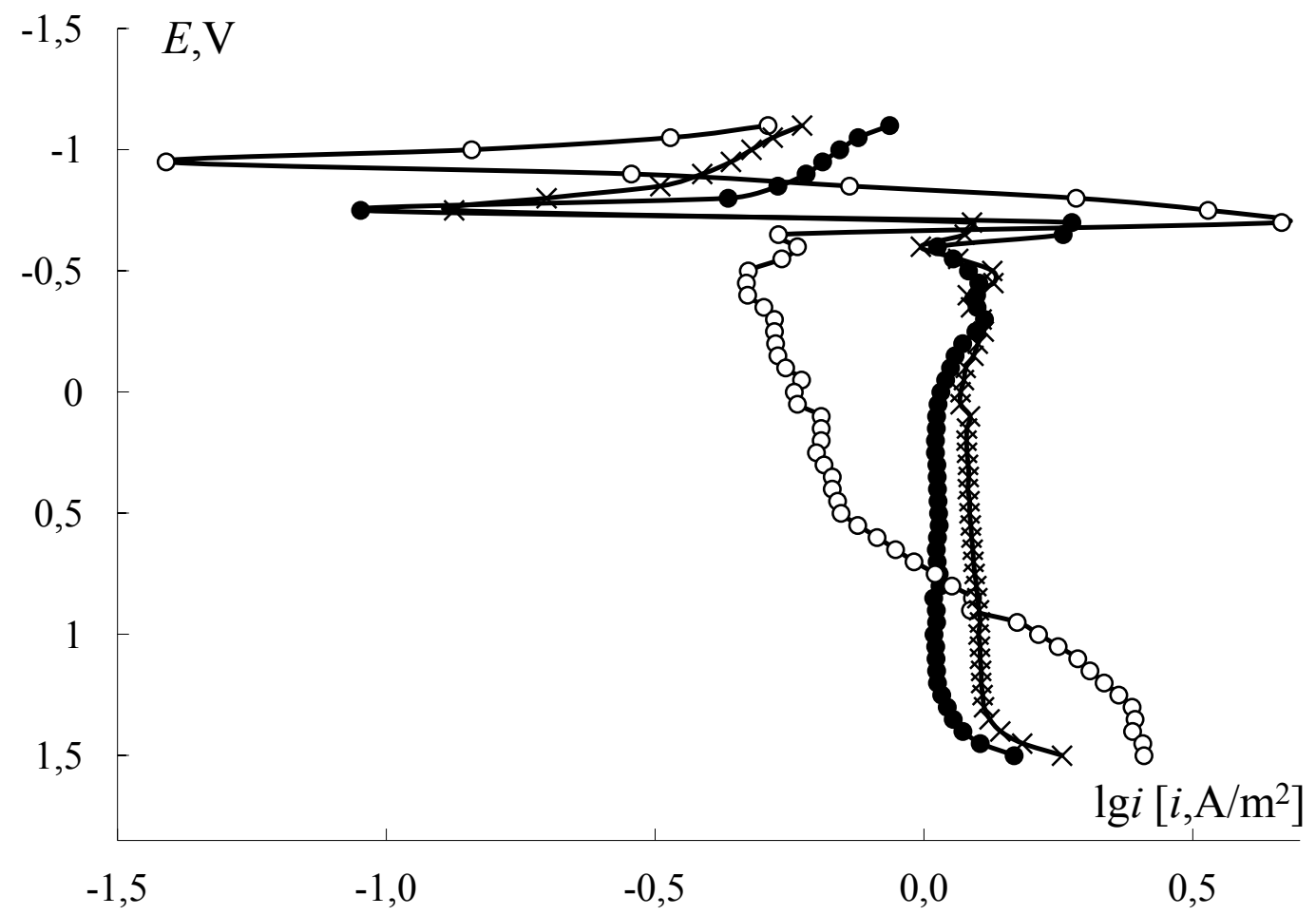

Fig. 1. Polarization curves of cadmium in pure borate solution $(\bullet)$ and in the presence of veratric acid (०) and 3,4-dimetylphenylanthranilic acid $(\times)$.

There are two peaks $E_{\mathrm{ap}, 1}$ and $E_{\mathrm{ap}, 2}$ on the polarization curve of cadmium, the first of which corresponds to the active-passive transition. The second one is expressed much less distinctly and may be caused by partial activation of the surface due to competitive adsorption of passivating and activating particles. At $E>-0.2 \mathrm{~V}$, the rate of the anodic process is stabilized and rather a broad area of stable passive state is observed, which is violated at $E=1.4-1.5 \mathrm{~V}$. The characteristics of the polarization curve on cadmium are presented in Table 1.

Organic acids differ in their effects on the cathodic hydrogen evolution rate and hence on the corrosion potential $E_{c o r}$, Table 1, Fig. 1. Veratric acid reduces the rate and polarization of the cathodic reaction more strongly and decreases $E_{c o r}$ by $0.225 \mathrm{~V}$. Dimethylphenylanthranilic acid has an inhibition effect on the cathodic reaction, nearly does not change polarizability and slightly decreases $E_{c o r}$ of cadmium. Due to an essential reduction in the corrosion potential, VA stimulates the active dissolution of cadmium, increases 2.4-fold the current of the first anodic peak $i_{\text {ap }, 1}$, but does not change its potential. It is obvious that VA forms sufficiently stable complexes with cadmium cations and does not prevent the formation of a passivating oxide-hydroxide film. The anodic reaction rate decreases significantly with a growth in potential, and the second peak is suppressed. The process rate in the stable passive state area is lower than in pure borate solution. However, 
the area of stable passive state is reduced essentially and at $E>0.6 \mathrm{~V}$ the current starts to increase. At $E>0.8 \mathrm{~V}$, inhibition of the anodic reaction is replaced by stimulation. Unlike veratric, acid DMPhAA inhibits the active dissolution of cadmium, decreases the current at $E_{\text {ap }, 1}$ and has almost no effect on it at $E_{\text {ap }, 2}$; at $E>0.55 \mathrm{~V}$ it increases the process rate, Fig. 1, Table 2.

Table 1. Dependence of some characteristics of polarization curves for cadmium and for the alloy.

\begin{tabular}{|c|c|c|c|c|c|c|}
\hline Additive & $-E_{\mathrm{cor}}, \mathrm{V}$ & $-E_{\mathrm{ap}, 1}, \mathbf{V}$ & $-E_{\mathrm{ap}, 2}, \mathbf{V}$ & $i_{\mathrm{ap}, \mathbf{1}}, \mathbf{A} / \mathbf{m}^{2}$ & $i_{\mathrm{ap}, 2}, \mathbf{A} / \mathbf{m}^{2}$ & $E_{\mathrm{tp}}, \mathrm{V}$ \\
\hline \multicolumn{7}{|c|}{ Cadmium } \\
\hline- & 0.725 & 0.7 & 0.5 & 1.9 & 1.2 & 1.5 \\
\hline VA & 0.950 & 0.7 & 0.5 & 4.6 & 0.5 & 0.7 \\
\hline DMPhAA & 0.775 & 0.7 & 0.5 & 1.2 & 1.3 & 1.5 \\
\hline \multicolumn{7}{|c|}{ Alloy } \\
\hline- & 0.720 & 0.65 & 0.4 & 0.7 & 1.3 & 1.4 \\
\hline VA & 0.747 & 0.65 & 0.4 & 1.6 & 1.4 & 1.4 \\
\hline DMPhAA & 0.743 & 0.65 & 0.4 & 1.8 & 1.4 & 1.4 \\
\hline
\end{tabular}

Table 2. Dependence of the inhibition factor of cathodic and anodic reactions on the nature and concentration of the additives and on the potential.

$\gamma$ value

\begin{tabular}{ccccccc}
\cline { 2 - 7 } $\boldsymbol{E} \mathbf{V}$ & \multicolumn{3}{c}{ Veratric acid } & & \multicolumn{3}{c}{ DMPhAA } \\
\cline { 2 - 7 } & $\mathbf{C d}$ & $\mathbf{B i}$ & $\mathbf{C d B i}$ & $\mathbf{C d}$ & $\mathbf{B i}$ & $\mathbf{C d B i}$ \\
\hline-0.9 & 2.1 & - & 1.3 & 1.6 & - & 1.61 \\
-0.8 & 0.2 & - & 1.3 & 2.2 & - & 1.6 \\
-0.7 & 0.4 & 2.0 & 0.3 & 1.5 & 2.0 & 0.3 \\
-0.65 & 3.4 & 2.3 & 0.7 & 1.5 & 2.0 & 0.7 \\
-0.6 & 1.8 & 2.4 & 1.0 & 1.2 & 1.9 & 0.4 \\
-0.55 & 2.1 & 2.5 & 0.9 & 1.0 & 1.7 & 1.0 \\
-0.5 & 2.6 & 2.6 & 0.9 & 1.0 & 1.5 & 1.0 \\
0.0 & 1.9 & 2.0 & 1.1 & 0.9 & 1.3 & 1.1 \\
0.5 & 1.5 & 2.4 & 1.1 & 0.9 & 1.4 & 1.2 \\
1.0 & 0.6 & 2.5 & 1.0 & 0.8 & 0.9 & 1.1 \\
1.2 & 0.5 & 2.6 & 1.0 & 0.8 & 1.0 & 1.1 \\
1.5 & 0.6 & 1.1 & 1.0 & 0.8 & 1.2 & 1.0 \\
\hline
\end{tabular}


The higher values of the process rate in the passive state may be conditioned by a decline in passivating film continuity due to surface blocking by DMPhAA.

Unlike cadmium, bismuth is passive already at $E_{c o r}$, Fig. 2 .

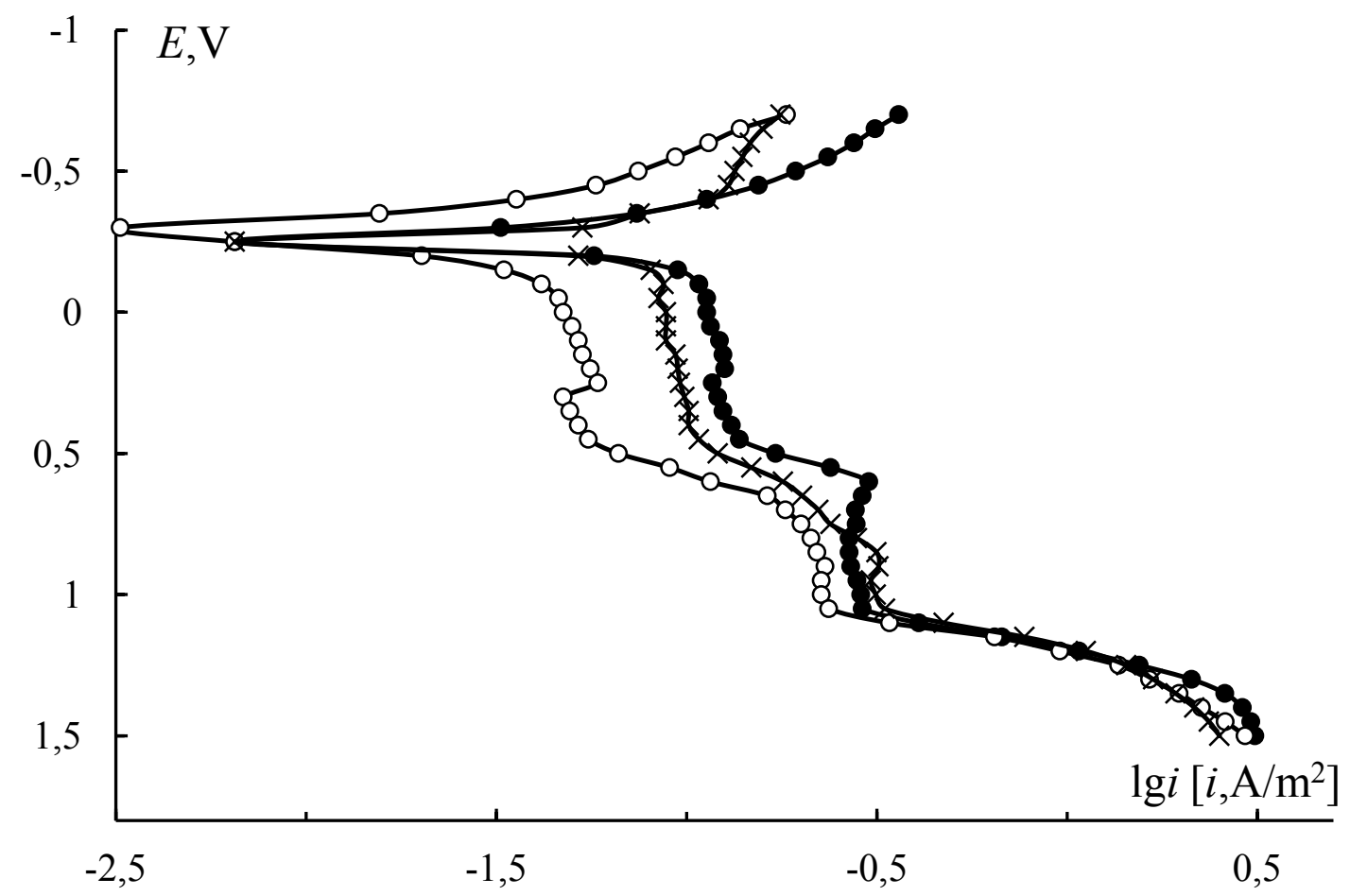

Fig. 2. Polarization curves of bismuth in pure borate solution $(\bullet)$ and in the presence of veratric acid (०) and 3,4-dimetylphenylanthranilic acid $(\times)$.

A step associated with transformation of bismuth oxide forms [4] is observed on the anodic polarization curve at $E=0.6 \mathrm{~V}$. As in the case of cadmium, VA shifts $E_{\text {cor }}$ to more negative values and reduces the hydrogen evolution rate more essentially than DMPhAA, Fig. 2, Table 2.

The anodic curves of the alloy and cadmium have a similarity, Fig. 3, Table 1. The character of the action of VA and DMPhAA on the cathodic and anodic reaction changes somewhat compared with the metals. Both acids shift $E_{c o r}$ to the cathodic area, which indicates that they primarily affect the hydrogen evolution rate.

The additives increase somewhat the dissolution rate of the alloy in the active state. Unlike with cadmium, DMPhAA is more efficient on the alloy, both for the cathodic and anodic reactions. Both acids increase the critical passivation current, have almost no effect on the current of the second anodic peak, and insignificantly decrease the anodic process rate in the stable passive region.

The alloy is hypereutectic with respect to cadmium. Its structural components include a fine-crystalline eutectics (phases of cadmium and bismuth intergrown into each other) and aggregated crystals of cadmium. The presence of different structural components on the alloy surface affects the regularities of its electrochemical behavior. 
This is especially obvious when comparing the experimental polarization curves with the model ones, Fig. 4.

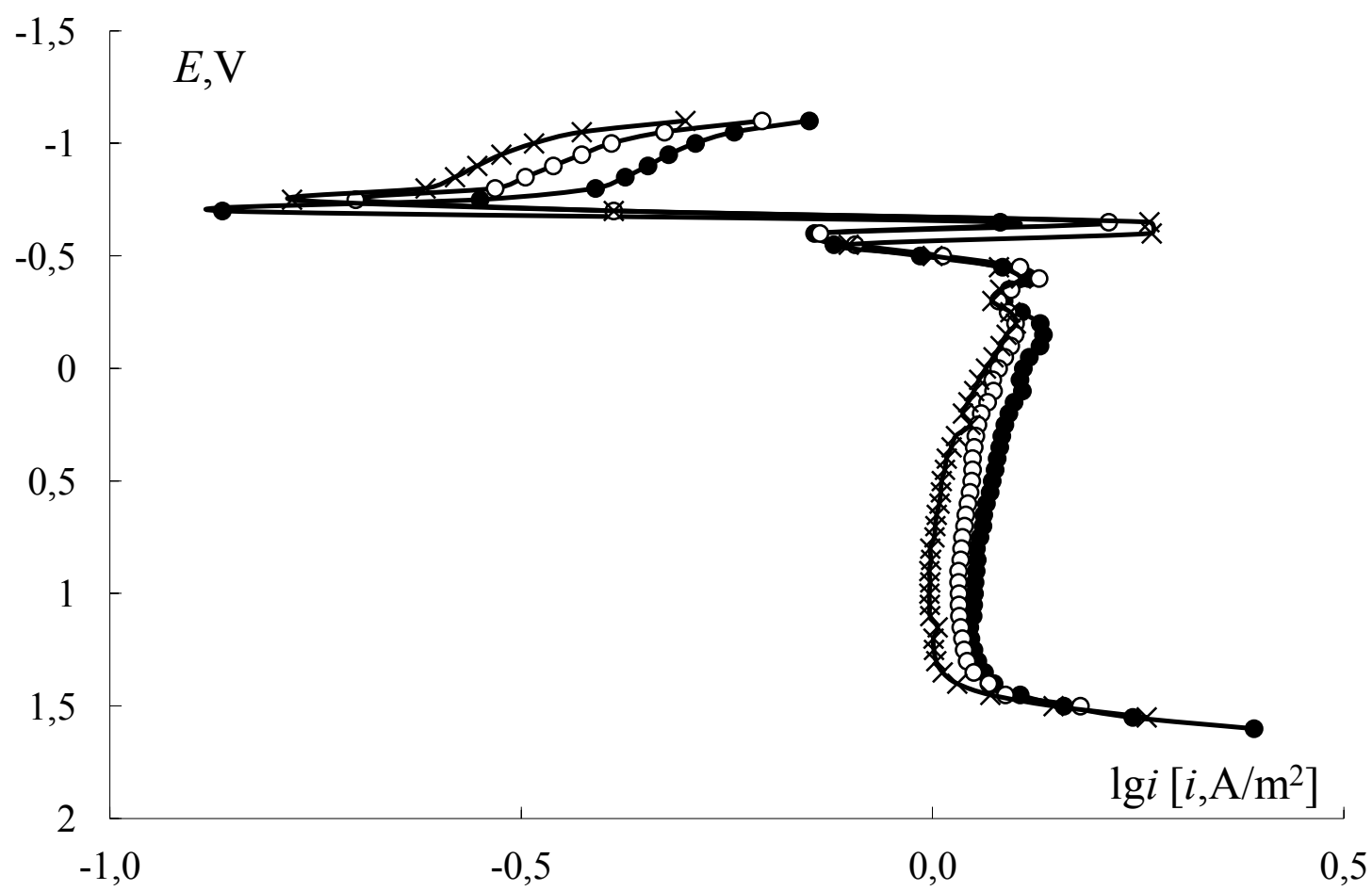

Fig. 3. Polarization curves of cadmium-bismuth alloy in pure borate solution $(\bullet)$ and in the presence of veratric acid ( $\circ)$ and 3,4-dimetylphenylanthranilic acid $(\times)$.

The model process rate values were calculated by the additive scheme: $i=N_{\mathrm{Cd}} i_{\mathrm{Cd}}+$ $N_{\mathrm{Bi}} i_{\mathrm{Bi}}$, where $N_{\mathrm{Cd}}$ and $N_{\mathrm{Bi}}, i_{\mathrm{Bi}}$ and $i_{\mathrm{Cd}}$ are the mole fractions of the metals and their rates, respectively. The calculated rates of cathodic and anodic processes at the majority of the potentials studied are smaller than the experimental ones. In the experimental curves, the passive state is violated at higher potentials in borate solution, both with and without the additives. This may indicate that the passivating films formed by mixed oxides or hydroxides of the components have higher protective properties.

\section{Conclusion}

In comparison with 3,4-dimetylphenylanthranilic acid, veratric acid has a more significant effect on corrosion and partial electrode reactions on cadmium and bismuth. A stable passive state of the cadmium-bismuth alloy in a wide range of potentials is provided by the formation of mixed oxides/hydroxides of the components. It is inappropriate to use the model constructed by the additive scheme for describing the electrochemical properties of eutectic alloys. 


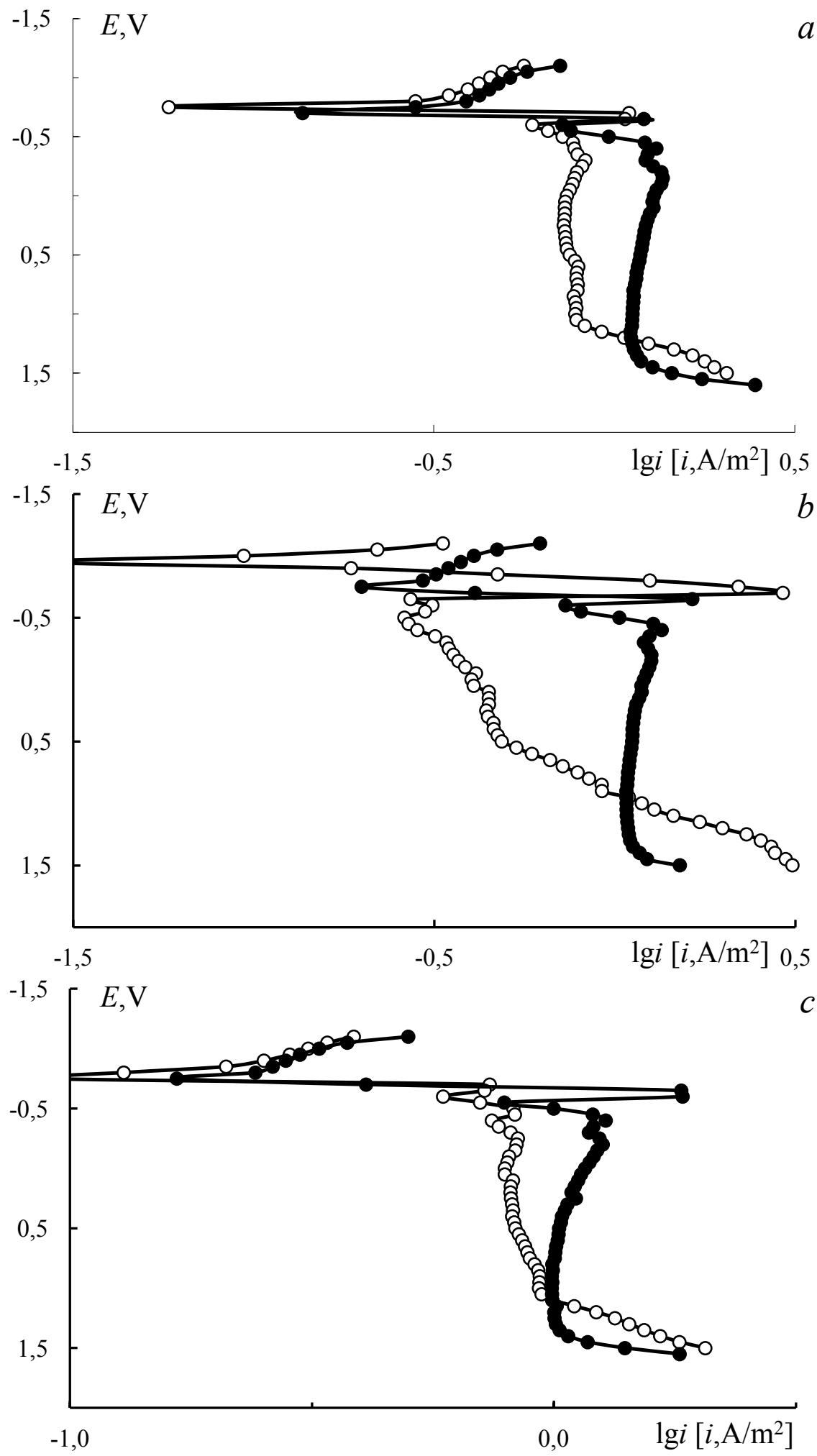

Fig. 4. Experimental $(\bullet)$ and calculated $(\circ)$ polarization curves of $\mathrm{CdBi}$ alloy in pure borate solution $(a)$ and in the presence of veratric acid $(b)$ and 3,4-dimetylphenylanthranilic acid $(c)$. 


\section{References}

1. A. G. Berezhnaya, V. I. Mishurov, V. V. Ekilik and L. A. Pavlova, Korroz.: Mater., Zashch., 2012, no. 5, 1 (in Russian).

2. A. G. Berezhnaya, V. I. Mishurov and V. V. Ekilik, Korroz.: Mater., Zashch., 2012, no. 11, 16 (in Russian).

3. A. G. Berezhnaya, Proceedings of the conference "Physicochemical processes in condensed media and at interfaces", FAGRAN-2008, Voronezh, 2008, 47 (in Russian).

4. B. N. Nikolsky, Spravochnik khimika (Chemist's Handbook), vol. 3, Khimiya Publishing House, 1965 (in Russian). 